septic and innocent quality of the sunlight just as we get it after filtration by the "unpolluted atmosphere:" But after seeing the clinical action of sunlight at Leysin under Dr, Rollier and at the Treloar Hospital under Sir Henry Gauvain, and reading the papers of Sonne (Acta Medica Scandinavica, vol. 54, fasc. 4, "The Mode of Action of the Universal Light Bath," from the Laboratory of the Finsen Medical Light Institute, Copenhagen) mentioned in my previous letter, I am absolutely certain, as anyone else would be, that there is more in the curative action of sunlight than its bactericidal effect. In a recent lecture before the Physiological Society of University College, entitled "The Physiology and Therapeutics of Sunlight: Facts and Questions:" I cited instances and showed photographs of many cases where the value of sunlight could not have depended upon its antiseptic power. Sonne's view is that sunlight warms the blood without appreciably raising the general body-temperature, that this produces the valuable, without the injurious, effects of fever, and that this action is obtainable by the proper use of sunlight, and by that alone.

The practical importance of this fascinating physiological problem is apparent to me after recent visits to certain sanatoria, otherwise admirable, where I have been told that I should see the sunlight employed, and have found, for instance, that open air and diffused daylight, the latter reaching the face and possibly the hands, were regarded as the equivalent of Rollier's treatment; or that the children were scrupulously put under awnings or sent to school in an adjacent wood whenever the sun shone. The pitiful statistics of these places, compared with those of Rollier and Gauvain, point the moral.

Since first drafting this letter I have seen, thanks to Prof. Leonard Hill, new records of work done by Prof. A. F. Hess in New York, showing the cure of experimental rickets in animals fed and continuing to be fed on a diet which invariably produces ricketswhen they were placed in sunlight for a few hours daily. No mere antiseptic action is here in question.

With rare exceptions, we do not yet know what heliotherapy consists of in this country; no one yet knows its action, nor even the pure physiology of sunlight. Meanwhile, we are carefully depriving many patients of their one chance of life, and quacks and others are using all manner of artificial lights in therapeutics as if they were equivalent to, or better than, the sunlight, which, according to Sonne's experiments-nicely consorting from another point of view with those of Sir Oliver Lodge-is incomparable.

The Smoke Abatement Committee has now published its admirable Final Report, and reiterates now my plea for an inquiry such as Carrel, I am told, is about to undertake at the Rockefeller Institute in New York, but which no one, not even Prof. Leonard Hill, our great student of the air and temperature relations of the body, is yet making here inte the action of sunlight. I believe that the restoration of sunlight to our urban populations, mostly darkened in slums and smoke, is the next great task of hygiene in this country.

Roval Institution, January 2 .

C. W. Saleeby.

\section{Units in Aeronautics.}

A LARGE number of equations. in aerodynamies appear in the form $\mathrm{R}=k \rho \mathrm{SV}^{2}$, where $\mathrm{R}, \rho, \mathrm{S}, \mathrm{V}$ are the reaction, density of the atmosphere, surface, and relative wind velocity.

Since both $R$ and $\rho \mathrm{SV}^{2}$ have the dimensions of force, $k$ is clearly a numerical coefficient unchanged NO. 2723 , VOL. IOg] by transformation from one self-consistent system of dynamical units to another, e.g. from foot, pound, second, poundal to centimetre, gram, second, dyne.

In transforming to an inconsistent system, $k$ will in general be altered, but the inconsistencies may cancel each other in particular cases so far as to leave $k$ unaltered. For example, if a gravitational unit of force is introduced $g$ times the consistent unit, then we may write $\mathrm{R}=k \rho \mathrm{SV}^{2} / g$ pounds weight in the British system, or grams weight in the c.g.s. system. And while the numerical values of both $R$ and $g$ vary inversely as each other, the value of $k$ is not affected if the system is otherwise consistent.

Prof. Bairstow ("Applied Aerodynamics," p. IIg) maintains that the gravitational unit of force is the natural one, and to get rid of the local value of $g$ that mars the consistency of his dynamical equations he introduces a new unit of mass, the "slug " of (local) $g$ pounds mass, the use of which he restricts to the measurement of atmospheric density. Then putting $\rho^{\prime}=\rho / g$ he can write $\mathrm{R}=k \rho^{\prime} \mathrm{SV}^{2}$ in the same form externally as before, and read off the value of $R$ in pounds weight instead of in poundals, all without showing $g$ explicitly:

In this way, in his opinion, "it appears that the divergence of language (sic) between science and engineering would disappear."

But if we apply this method of measuring the density of the atmosphiere to the estimation of the lift of an aerostat we get, putting $m=$ density of hydrogen/density of air, $(1-m) \rho^{\prime} \times$ volume $=R$ slugs weight ( $=g \mathrm{R}$ pounds weight $=g^{2} \mathrm{R}$ poundals!).

Altogether it seems more satisfactory to teach engineers the physical meaning of Newton's laws of motion than to invent units which evade them, just as it has proved better to teach them the elementary notation of the infinitesimal calculus than to devise "calculus-dodging" demonstrations. A. R. I.ow.

London, December 8.

\section{Self-fertilisation in Mollusca.}

As the question of self-fertilisation in the more highly organised invertebrates is of considerable importance from the genetic point of view, I would like to direct the attention of readers of NATURE to a publication (Acta Soc. pro Fauna et Flora Fennica, vol. 40, No. 2, I915), a copy of which I have just received from the author, Dr. A. Luther. It constitutes an important addition to the evidence for the occurrence of self-fertilisation in mollusca, as Dr. Luther states that he succeeded in rearing two generations by selffertilisation in Agriolimax agrestis. I have recently pointed out (Proc. Malac. Soc., vol. I4, r92I) the value of Künkel's work on Arion in this respect; but at the time Dr. Luther's results were not known to $m e$, as the publication was not available and had not figured in the "Zoological Record." Should these important observations be finally confirmed and the technique improved so as to produce more than two generations, a very valuable contribution to genetic study will be achieved. Dr. Luther's work, however, emphasises the necessity for conducting a study of environmental conditions in order to secure improved viability.

I may point out, perhaps, that though quite a number of cases of self-fertilisation have been recorded in Pulmonata by Lang, Holzfuss, and others, the subject is by no means fully explored either with regard to the distribution of the phenomenon among Pulmonata or the circumstances in which it occurs.

British Museum (Natural History), G. C. Róbson.

Cromwell Road, London, S.W.7, December 23. 